Pre-print of the published article: Juliane Jarke (2019). Open government for all? Co-creating digital public services for older adults through data walks. In: Online Information Review,

\title{
Open government for all? Co-creating digital public services for older adults through data walks
}

\section{Juliane Jarke}

Centre for Media, Communication and Information Research (ZeMKI) \& Institute for Information Management Bremen (ifib), University of Bremen, Bremen, Germany

Email: jarke@uni-bremen.de; Twitter: @juliane_jarke

\begin{abstract}
Purpose - The purpose of this paper is to review interventions/methods for engaging older adults in meaningful digital public service design by enabling them to engage critically and productively with open data and civic tech.
\end{abstract}

Design/methodology/approach - The paper evalutes data walks as a method for engaging non-techsavvy citizens in co-design work. These were evaluated along a framework considering how such interventions allow for sharing control (e.g. over design decisions), sharing expertise and enabling change.

Findings - Within a co-creation project, different types of data walks may be conducted, including ideation walks, data co-creation walks or user test walks. These complement each other with respect to how they facilitate the sharing of control and expertise, and enable change for a variety of older citizens.

Practical implications - Data walks are a method with a low-threshold, potentially enabling a variety of citizens to engage in co-design activities relating to open government and civic tech.

Social implications - Such methods address the digital divide and further social participation of nontech-savvy citizens. They value the resources and expertise of older adults as co-designers and partners, and counter stereotypical ideas about age and ageing.

Originality/value - This pilot study demonstrates how data walks can be incorporated into larger cocreation projects.

Keywords Co-production, Co-creation, Co-design, Open data, Open government, Data walks

Paper type Research paper 


\section{Introduction}

Open Government promotes the idea of citizen collaboration and participation in the planning, design and delivery of public services. The approach has been accelerated through the Open Government Partnership, an association of more than 90 national and regional governments that have committed themselves to become more open and to develop biannual National Action Plans in cooperation with civil society organisations. The idea of using open government data for new public services is simple: Governments provide their data for free, online and under open licences; civil society actors or private companies may re-use the data and develop services according to their needs or expected demand. In some cases, these co-created services are then integrated into egovernment service portals. Thus, the vision is that governments can offer user-centred services without additional costs; citizens receive better services via successful and beneficial public engagement and participation (Janssen et al., 2012, p. 261).

With signing the Open Government Partnership, governments commit themselves to cooperate with Civil Society. The civil society constituency working with open government data mainly includes civic tech activists (also called civic hackers), who are 'deploying information technology tools to enrich civic life, or to solve particular problems of a civic nature' as Hogge (2010, p. 10) noted in a study commissioned by the Open Society Foundation. So far, the field of civic open data use (civic technology) is dominated by younger and tech-savvy 'civic hackers' that develop services for their communities and cities (Gooch et al., 2018; Lee et al., 2015).

Older citizens - if at all-are often only marginally involved in such kinds of civic technology engagement. They very rarely constitute the focal user group of civic apps. Considering the ageing population and the specific needs of older adults for usable and accessible public services, there is an articulated need to bring together city administrations as data owners, technology developers and older citizens as knowledgeable individuals and prospective users in order to co-create relevant and meaningful public services based on open data. However, most research and innovation in this area so far focuses on the use and re-use of existing open data sets, assuming that the data is easily available. Our research shows that the pledge to citizen-centricity requires additional engagement in acquiring and/or producing data, which are considered relevant by citizens. This requires new ways of engaging citizens, in particular those not familiar with technology design and use.

This paper is based on our own action research in co-creating digital public services with older adults. We report on a pilot study conducted between April and December 2017 in Bremen, Germany as part of a larger, EU-funded research and innovation project. This paper reviews interventions for engaging older adults in meaningful open service design by enabling them to engage critically and productively with open data. We argue that in order to enable older adults to become co-creators, we need to reconfigure and develop new and creative ways for engagement. Taking a situated, practice-based approach as a starting point for technology design, these methods need to relate to the everyday of participants and establish them as experts. We present and discuss the idea of walking workshops as a way to co-create digital public services, which are relevant and meaningful in the everyday life of older adults (for other methods see e.g. Jarke and Gerhard, 2018). However, such methods come with their own challenges e.g. concerning the sustainability and maintenance of these data.

In the following sections, we will firstly outline why it is important to consider new ways of engaging citizens when pursuing open government. We present co-creation as a way to engage different groups of citizens and discuss different roles that citizens may assume in such participatory approaches, before introducing walking workshops as an experimental method from the field of 
critical data studies, which allows for creative ways of engaging with data. We analyse our approach to using walking workshops as a method of co-design with respect to its inclusiveness and the extent to which it allowed us to consider the needs and interests of participants. We conclude by arguing that walking workshops are a promising method for engaging older adults in co-design activities.

\section{Related work: Co-creating digital public services}

\section{Co-creating digital public services for and with older adults}

Interactions between public authorities and citizens are increasingly mediated by digital technologies as more and more public services are provided via digital channels. However, in many cases these services are not used widely and in particular, older citizens are excluded above average, as digital services do not meet their needs and expectations. Over the last decade, the idea of open government (European Commission, 2014; House - Oversight and Government Reform, 2007; Office of the President, 2009; Presidential Directives EO 13392, 2005) has attracted attention, encouraging participation and collaboration between governments and citizens to plan, design and provide (digital) public services. One way to perform this collaboration is through the civic use of open government data. Sieber and Johnson (2015) have identified four different approaches in which governments and citizens can interact. These approaches span from the mere provision of data by government and data use through citizens to the active co-creation of data and services through both sides:

(1) Data Publishing: Governments provide data as open data via local or national portals. According to the requirements of the Open Knowledge Foundation, Open Data should be freely available to everyone to use, re-usable and re-publishable as users wish, and absent mechanisms of control such as restrictive licenses.

(2) Code exchange: Government explicitly encourages the development of saleable or internally useful products based on its provision of open data as mentioned in the introduction. The provision of data is accompanied by promotional or other forms of supportive activity and is often framed in the context of an 'app contest', i.e. apps developed by a developer community, including private business and civil society. It is a kind of outsourcing app development by government.

(3) Civic Issue Tracker: In this model, the direction of interaction is reversed. Government invites citizens to report problems like potholes or noise complaints or to give feedback on published data and documents. This model may be applied independently from the two previous models, but can also be combined, when citizens are invited to act as 'sensors of their environments' and report data on phenomena they are physically close to in a crowdsourcing approach.

(4) Participatory Open Data: Here open data is reciprocal. Data provision from authoritative sources may be followed by a request for additional data and be amended by citizengenerated data that can support service delivery and open a new channel for discussions about policy. This can take place in a co-management framework and includes the on-going co-creation of raw data between both governments and governed and the co-production of services (Sieber and Johnson, 2015).

Sieber and Johnson see governments 'at a crossroad' taking a choice between these models, as they are driven by different motivations: The first two models are motivated by the call for transparency based on freedom of information requirements and/or providing resources for economic 
development. The third model is motivated by a concern for more responsive relation of government to its citizens while the fourth model demonstrates a fundamental change of the roles of government and calls for a degree of flexibility, which is hardly found. However, the authors promote the 'Participatory Open Data Model', because the first two models pose the risk that governments 'outsource themselves'. If, for example, Google collects all public transport data and offers transport information, people may start asking why they pay taxes if others provide public services for free. In the authors' view, the forth model is a necessary reaction to ongoing changes in the digital world and in line with the principles of the Open Government Partnership.

The idea that people outside an organisation are involved in the development of information services, is prominent in the context of civic tech, where so-called civic hackers use open government data to design civic apps which offer and, at times, substitute for public services (Schrock, 2016). In principal civic tech may involve anybody 'who is willing to collaborate with others to create, build, and invent open source solutions using publicly released data, code and technology to solve challenges' relevant to their neighbourhoods, cities or states. Hence, it aims to engage citizens (including those with non-technical backgrounds) in practices relating to different types of open data use such as the requesting, digesting, contributing, modelling, and contesting of open data (Schrock, 2016). However, civic tech apps are mainly developed in app competitions and hackathons (often run by public administrations) or through continuous civic tech work such as CodeForAmerica. Software development in such settings is rarely participatory and the resulting apps do not necessarily relate to the needs of other citizens (Lee et al., 2015).

Often civic tech developers anticipate the needs and wants of citizens based on their own experiences with lack or insufficient knowledge about other prospective user groups. However, in order to create value that benefits administrations as well as citizens, it is crucial to engage citizens who are often forgotten when it comes to technological innovations. This implies a citizen-driven rather than a data-driven approach that takes citizens' everyday practices as the starting point instead of embarking from the data sets available.

When considering the co-creation of digital services specifically, there is a long tradition of user involvement in Information System Development (ISD). Ever since the users of Information Systems (IS) became a different group of professionals from those that design and implement such systems, there was a gap between the expertise of professional software systems developers and prospective users. By involving users in the software design, their specific expertise about the use context and how they may be supported can be fed into the requirements specification. Although user involvement usually involves higher costs, there is agreement that the outcome of such involvement leads to higher user satisfaction and take-up (e.g. Vines et al., 2013; Bratteteig and Wagner, 2016; Ehn, 2008).

The success of participatory service design projects depends on the involvement of appropriate and representative users (Gidlund, 2012). The roles of citizens differ across the spectrum of these approaches. While participation in some co-creation initiatives is limited to the co-design of an interface of an application, others also involve citizens in generating topics and contents. Hence, participants can take different roles. In general, the roles citizens may assume have been either,

- defined along the service design and provision process - plan, build, run (e.g. Voorberg et al., 2015):

- Citizens as initiator

- Citizens as co-designers

- Citizens as implementers 
- Or, with respect to specific tasks - exploring, forming ideas, designing, diffusing (e.g. Nambisan and Nambisan, 2013):

- Explorer: Identify problems to be solved

- Idea former: Generate solutions to well defined problems

- Designer: Design and/or develop implementable solutions

- Diffuser: Facilitate the adoption and diffusion of the developed solution

When it comes to software design for older adults, most software development projects are based on the designers' assumptions regarding older people's needs. However, critical scholars in STSinspired social gerontology but also human-computer interaction demand a more critical engagement with technology design for older adults (e.g. Peine et al., 2015; Neven, 2011; Wanka and Gallistl, 2018). In particular, they question the representations of 'age' that are often scripted into technologies and call attention to the potential consequences of their use. Engaging older adults prior to the design process, embraces alternative measures and attributes of 'success' in later life" (Vines et al., 2015, p. 20). Amongst others, these changes and extensions to the meanings of becoming old reveal the diversity and heterogeneity amongst the group of older people (Höppner and Urban, 2018). However, so far there are few studies when it comes to digital services co-design with older adults. What is hence required are the development and evaluation of interventions and methods for engaging older adults in meaningful ways. In the following, we present a method that has been applied and adapted in critical interventions to smart cities: walking workshops or data walks. Data walks are particularly interesting with respect to co-design projects with older adults as they directly relate to everyday practices and experiences while at the same time allow for a critical engagement with data.

\section{Experimental ways of citizen engagement with data: Data walkshops}

Walking is a human activity, engrained in urban and rural culture. It is also becoming a prominent method in projects related to data and critical data studies (Wieringa and van Es, 2018) as well as participatory design (Kanstrup et al., 2014). What makes such walks an interesting and important tool for engaging (critically) with data is their embeddedness in everyday urban life. Data walks have been proposed and conducted in a number of projects aiming to engage with data and putting an 'emphasis on the everyday experience of data' (Wieringa and van Es, 2018) as well as the relationality of design (Kanstrup et al., 2014).

Wieringa and van Es (2018) have mapped a number of different formats each comprising of different set-ups and goals. For example Greenfield \& Kim (2011) set out to raise awareness/literacy on 'networked urbanism' among citizens. Van Zoonen et al. (2017) took city employees on walks through their own smart city. While Greenfield \& Kim only delimited an area on a map, Van Zoonen et al. defined the routes beforehand. The focus of their walks was 'identifying big data in the city and connecting it to political and ethical issues' (Wieringa and van Es, 2018). In so doing, Van Zoonen et al. not only raised awareness on data issues amongst civil servants, they also learned about the knowledge and beliefs of their participants with respect to the datafication of their city. Building on Greenfield and Kim, Powell (2018) experimented with different forms of data walks: initially to teach students about big data related to urban issues, later to create 'bottom-up knowledge'. In her walks, participants assumed different roles from note-taker to photographers. Yet another format of data walks was conducted by Hunter (2018), who did not only want to raise awareness amongst participants but also collected environmental data on specific areas and built multi-layered 'dataspaces'. Table 1 provides an overview on these different types of walks.

Table 1: Inventory of different data walks [excerpt from Wieringa \& van Es 2018) 


\begin{tabular}{|c|c|c|c|c|}
\hline & Greenfield \& Kim & Powell & Van Zoonen et al. & Hunter \\
\hline Type of walkshop & $\begin{array}{l}\text { Networked } \\
\text { urbanism }\end{array}$ & Data walks & Data walks & Data walk \\
\hline Goals & $\begin{array}{l}\text { Raising } \\
\text { awareness/ } \\
\text { literacy on } \\
\text { 'networked } \\
\text { urbanism' }\end{array}$ & $\begin{array}{l}\text { Originally teaching } \\
\text { tool against } \\
\text { celebratory } \\
\text { rhetoric. Now } \\
\text { raising awareness } \\
\text { and 'creating } \\
\text { bottom-up } \\
\text { knowledge' }\end{array}$ & $\begin{array}{l}\text { Gaining insight } \\
\text { into civil servants' } \\
\text { ideas and beliefs } \\
\text { about datafication, } \\
\text { and "strengthening } \\
\text { their critical } \\
\text { interrogative } \\
\text { attitude" (p. 1) }\end{array}$ & $\begin{array}{l}\text { Examining tools } \\
\text { and technology fo } \\
\text { data collection, } \\
\text { and experimenting } \\
\text { with data } \\
\text { visualisation }\end{array}$ \\
\hline $\begin{array}{l}\text { Number of } \\
\text { participants }\end{array}$ & 15 & $\begin{array}{l}5 \text { per team (with a } \\
\text { max of } 15 \text { ) }\end{array}$ & $4-6$ & - \\
\hline $\begin{array}{l}\text { Type of } \\
\text { participants }\end{array}$ & $\begin{array}{l}\text { Mix of locals and } \\
\text { domain experts }\end{array}$ & $\begin{array}{l}\text { Different } \\
\text { audiences. } \\
\text { Originally } \\
\text { students, now } \\
\text { citizens }\end{array}$ & Civil servants & $\begin{array}{l}\text { Different } \\
\text { audiences (e.g. } \\
\text { students, } \\
\text { conference } \\
\text { visitors) }\end{array}$ \\
\hline $\begin{array}{l}\text { Roles of } \\
\text { participants }\end{array}$ & - & $\begin{array}{l}\text { Navigator } \\
\text { Photographer } \\
\text { Map-maker } \\
\text { Note-taker } \\
\text { Collector }\end{array}$ & $\begin{array}{l}\text { Participants } \\
\text { Participant } \\
\text { observers }\end{array}$ & - \\
\hline Duration of walk & $90 \mathrm{~min}$ & $60 \mathrm{~min}$ & $60 \mathrm{~min}$ & Different lengths \\
\hline Duration of event & Half a day & Half a day & $"$ & $\begin{array}{l}\text { Different lengths, } \\
\text { from } 3 \text { days }-45 \\
\text { min. May be } \\
\text { repeated } \\
\text { throughout the } \\
\text { year. }\end{array}$ \\
\hline Event makeup & Walk - discussion & $\begin{array}{l}\text { Briefing - walk - } \\
\text { critical making }\end{array}$ & Walk - debriefing & $\begin{array}{l}\text { Preparation - walk } \\
\text { - visualisation }\end{array}$ \\
\hline
\end{tabular}

Walking and mobility within the immediate environment are particularly relevant when engaging older adults. In the context of co-creation with older adults it relates to the importance of ageing in place and neighbourhood (Wiles et al., 2012; Manchester and Facer, 2016). A study conducted by Wiles et al. (2012) characterises 'ageing in place' by the positive perceptions of older adults as a sense of attachment and social connection, a sense of security and familiarity and a sense of identity, linked to independence and autonomy. To assist older adults to remain in their communities and neighbourhoods with some level of independence, rather than in residential care homes, requires to consider not only their immediate housing options but also 'transportation, recreational opportunities, and amenities that facilitate physical activity, social interaction, cultural engagement, and ongoing education' (Wiles et al., 2012). Appropriate information about the available resources in a neighbourhood can have a positive effect on social participation, if it relates to the (mediated) information practices, the abilities and limitations of older adults (Beneito-Montagut et al., 2018). 
One question that participatory design approaches allow to ask is what kind of (digital) information is relevant and useful to (a variety of) older adults and what kind of data, data visualisations and data processing (e.g. filtering, searching) are required in order to provide this information. In the following, we present three dimensions along which we will evaluate the format of walking workshops for engaging older adults in the co-creation of digital public services. These dimensions are based on the objectives of participatory design projects and hence also hold up to methods aiming to engage future users in participatory open data projects.

\section{Evaluation Framework}

\section{Sharing control: Openness and diversity of process}

Rooted in the political agenda of Scandinavian participatory design, one of the main aims of participatory approaches is the destabilisation of power structures by sharing control over the design process and outcome (Vines et al., 2013). This is grounded in a moral proposition: Participatory design is commendable because 'the people whose activity and experiences will ultimately be affected most directly by a design outcome ought to have a substantive say in what that outcome is' (Carroll and Rosson, 2007, p. 243). Humans ought to be regarded as 'actors', not 'factors' (Bødker, 2006).

Hence, when a co-creation process shall lead to a relevant and user-centered service for a certain target audience, the process has to be open for members of this target audience. If there is a heterogeneous target audience one of the criteria for an effective engagement process is to make it equally accessible to the different subgroups. Walking workshops hence need to be evaluated as interventions that ensure openness and diversity.

\section{Sharing expertise: Older adults as experts in co-creation processes}

To include future users' input in the design process increases the chances of a successful design outcome by taking into account their 'expert perspectives and preferences regarding the activity that the design will support, and most likely transform' (Carroll and Rosson, 2007, p. 243). Pragmatically hence, it is argued that 'having the users participate makes it easier to implement the design result' (Bratteteig and Wagner, 2016, p. 426). One of the most common ways of eliciting users' expertise are workshops in which teams of researchers, designers, system developers, future users and other stakeholders come together to identify challenges and develop new ideas. In these workshops 'boundary objects' (Star and Griesemer, 1989) are co-developed that act as 'shared articulations of knowledge of those participating in the design process' (Vines et al., 2013, p. 430). Depending on the design context and the quality of user participation, the interpretative weight of the design team differs.

Walking workshops are one format in which encounters between future users, designers and other stakeholders may happen. When considering the suitability of this format it is important to evaluate to what extent it enables participating older adults to assume the role of experts and facilitates their role-shift from passive design subjects to active participants (Sanders and Stappers, 2008; Jarke and Gerhard, 2018). 


\section{Enabling change: Relevance of process and value of outcome}

Another important criterion to evaluate is the quality of interventions in a co-creation process with respect to their relevance for participants. In order to assess how relevant interventions were to the participants and to what extent their needs and interests were considered, the following questions need to be asked:

- What were the needs and interests that motivated participants to join?

- To which extent and how did the interventions address these needs, interests and motivations?

- How relevant, interesting and useful were the interventions?

- Did the process have any relevance beyond the participants?

Participatory design approaches aim to enable some kind of change. In order to do so, interventions need to allow designers to understand peoples' current practices, experiences and how future design products may become appropriated (Vines et al., 2013). As such, the output of a co-creation process (e.g. digital public service) refers to a social innovation in the form of software and data that is embedded into a larger public online portal and provided to the general public. The value of such a service for older adults needs to meet the central value proposition of open government and provide a more relevant service of higher quality and better accessibility than existing services.

\section{Case study: Data walkshops in Bremen}

\section{Background}

In this paper, we are reporting on our experience of data walks as a method for co-creation with older residents. The co-creation project was conducted in a district in one of the project's field sites: Bremen Hemelingen, Germany between April and December 2017. It resulted in a digital neighbourhood guide, which is now provided via the city information portal.

District 1 is split into various neighbourhoods that are both physically and socially segregated from one another. In close coordination with the local intermediaries and social care providers that were already engaged in the wider research project, we developed the idea of co-designing a digital walking guide that would provide relevant and appealing information on walks in the district, and support the social aspect of walking by providing some kind of organisation and/or communication tool. Throughout the process, the value proposition of the service came to be formulated as follows: Provide relevant and appealing information to older adults which activates and motivates group walks in the district and supports service providers in organising and announcing these kinds of walks by exploiting the full potential of multimedia technologies.

The research in this project was conducted by following an action research approach (Hayes, 2011). We carefully planned each of our interventions, observed and documented them and adjusted further interventions accordingly. We used a reflective learning journal for documenting our interventions. This learning journal documented for each intervention the date, its length, the number of participants as well as the objectives of the intervention, a description of methods and activities, the results and a reflection on e.g. the appropriateness of methods or surprising outcomes.

In total 46 older adults from the district were engaged throughout the process. A core group of six people participated in almost all walks and continued to engage in subsequent design and prototyping activities as well. In addition, 10 intermediaries and service providers were engaged 
throughout the process. A project board that consulted us on an ongoing and regular basis consisted of seven service providers and intermediaries. We conducted eight focus groups with older adults throughout the process. In addition, we conducted four interviews with members of the project board during the process and four interviews with social care service providers and local government after the process. Those interviews were recorded and transcribed, and analysed using thematic analysis (Guest et al., 2012).

\section{Recruitment of participants}

The target audience of the app was broadly defined as so-called $3^{\text {rd }}$ agers - older adults still relatively mobile and independent ${ }^{1}$. The recruitment was open to a broad range of older adults, and participants of the co-creation process were, to some extent, self-selecting. Furthermore, the participants themselves defined what characteristics made a difference with respect to experiencing ageing in their neighbourhood. The target audience of the co-creation process hence became refined throughout the process and continuous engagement with participating older adults and intermediaries. The refinement of the target audience helped narrowing down the 'problem focus' and defining a service.

Recruiting participants for a co-creation process whose outcome is somewhat undefined by nature and with tasks unfamiliar to most older adults was a great challenge. Our recruitment strategy for older adults considered the different requirements and emphasised that digital skills were welcome, but that other competencies such as good local knowledge was equally important. We set up a project board in order to engage local stakeholders and to facilitate the recruitment of older citizens. The local service providers and intermediaries that were engaged in the project board supported the recruitment through individual address, via leaflets and through newspaper articles. Engaged participants also often invited acquaintances.

\section{Phase 1: Detailing the service idea for digital walks}

In order to detail the concept for a digital service and define the data (categories), a first walking workshop was conducted in June 2017 together with a social activity manager of a senior citizen centre. The participants were recruited through the staff of the senior citizen centre but also via newspaper announcements. Most participants could walk without support, few had walking aides. The intended goal was to identify relevant attributes for walking routes (what information older adults need or are interested in on walking routes). In addition, the aim was to raise interest in the project so that participants would become engaged throughout the process.

The route had been defined in a preceding meeting with the project board. The announcements in the newspapers foregrounded the joint walk through the neighbourhood rather than the technology focus of the project itself, in order to keep the barriers for participation low. It was planned to walk together along the route and fill out a questionnaire on what attributes may be considered relevant. The questionnaire had been developed based on literature on accessible and age-friendly neighbourhoods and cities by the team facilitating the project. It asked the participants 'to mark

\footnotetext{
${ }^{1}$ Laslett's (1991) distinction of the 3rd and 4th age is helpful in defining the target audience of a service, since the specific needs of older adults differ not so much with regard to their biological age but to their life circumstances, capabilities and needs.
} 
what you think is important for the description of walks and paths and make notes if you have discovered something accordingly on the way' and offer response items in the following areas:

- Points of interest (Architecture/buildings, historical, green areas, art, other)

- Helpful things (benches, restrooms, railing/handrails, street greening (shade), illumination, other)

- Useful things (shops, services, sport, playgrounds, other)

- Rest points/provision of food and drinks (cafés, restaurants, kiosk, bars, other)

- Sidewalks (Inclination/longitudinal and/or transverse inclinations, narrow places, separation of footpaths and cycle paths, obstacles, breadth, height of the curb, cleanness, surface condition, other)

- Road crossing/unavoidable road use (traffic light available, traffic island available, lowered curb, surface of the road to be crossed

- Size (lanes/tracks) of the road, traffic intensity, pace, other)

- Annoying things (dog excrement, dirt/waste, noise, smell, cyclists on footpaths, other)

- Public transport stops (shelter, other)

Nine older residents from the district participated in the first walk. Most of them had lived there for a long time and were very knowledgeable about it. They had a lot to tell about the historical developments in the district, which turned out to be a main point of interest for walks.

The analysis of the questionnaire confirmed the impression that the participants were more interested in historical and recreational attributes than in information on accessibility. Five participants were interested in architecture and buildings; four were interested in historical information. Six were interested in recreational spaces. While seven stated to appreciate information on benches and toilets, only three were interested in information about traffic lights and almost none listed any of the attributes concerning the pavement and the road crossing. In a subsequent focus group, which was meant as a debrief of the results, it became apparent that, in addition to the accessibility of walks, a thematic focus of the digital walking guide on historical and recreational walks was commended.

The results of this first walk confronted us with the recognition that the data required to realise this co-created service concept were not available. We had expected that the target group would be particularly interested in the accessibility of routes and buildings, public transport, benches, toilets, restaurants and other practical aspects, on which open data sets are (easily) available. However, we quickly realised that the required information on the history of and stories about the district as well as tips about recreational places (e.g. for walking) was not available: All of the participants had their personal stories to tell which revealed surprising and interesting facts about the historical development of the neighbourhood. Some of them knew places unknown to the others they wanted to share. In order to collect this local knowledge and make it available via a digital service to a broad range of older adults in the district, we started conducting data co-creation walks.

\section{Phase 2: Conducting data co-creation walks}

The walks were collaboratively defined with different stakeholders. They differed in their scope and framing:

- Walks in parks and recreational areas (walks 1 - 4)

Three of the walks were conducted in collaboration with the senior citizen meeting place in one of the neighbourhoods.

- Guided historical walks (walks 5 - 6) 
We conducted two walks that were each conducted by an older resident that talked about the neighbourhoods' history.

Each walk was announced via the local newspapers, the district's website as well as the network of service providers. They were between 2 and $3 \mathrm{~km}$ and lasted between 1,5 and 2 hours. This time was proposed by the network of service providers (project board) as most suitable (also for people with mobility issues) and contained time for breaks. The starting points were well-known places in the district and reachable by public transport. Each of the walks included at least one stop for either lunch or cake \& coffee. The descriptions of the walks featured places with lunch offers for older adults or coffee $\&$ cake as well as public toilets and benches. Figure 1 presents an overview of the different stakeholders participating in the walks.

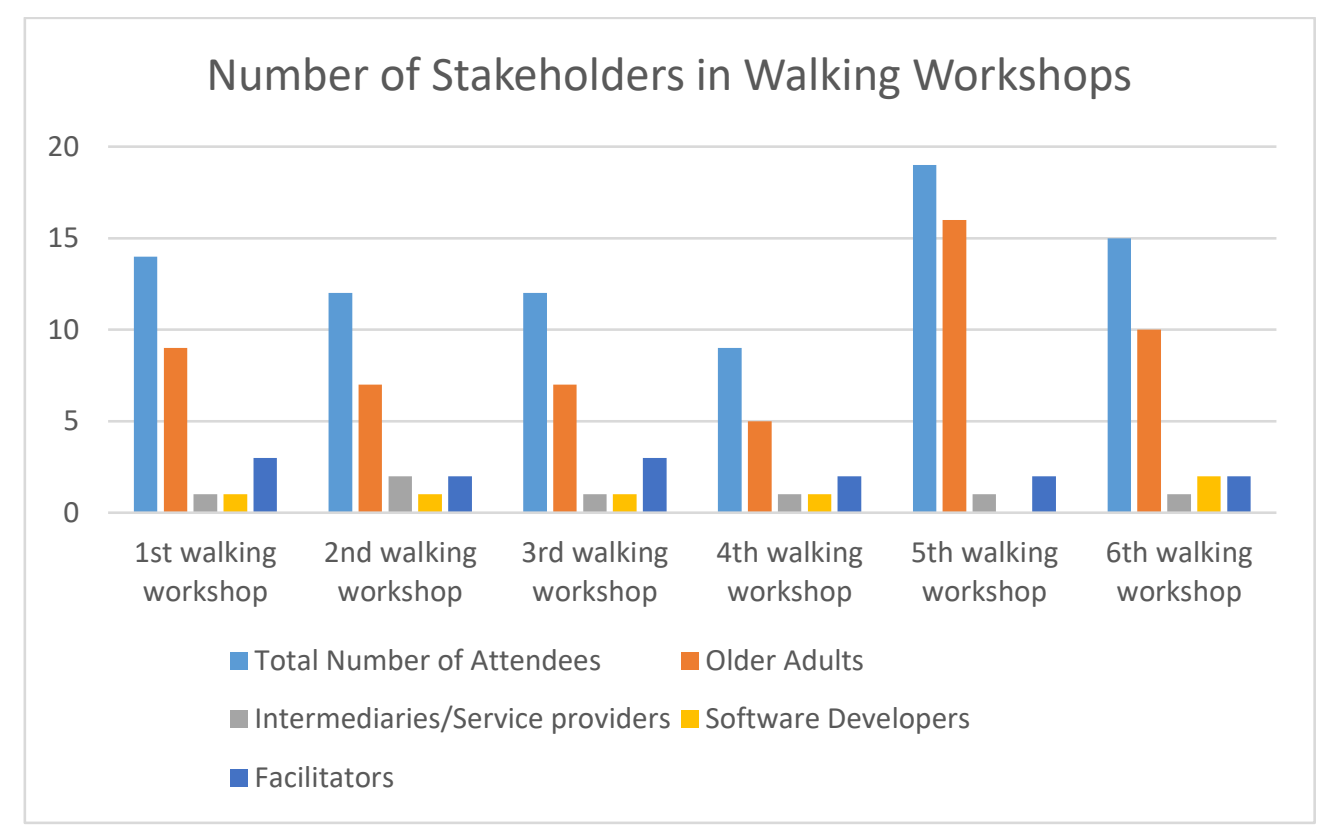

Figure 1: Number of stakeholders in walking workshops

The older participants and service providers assumed different roles in the walks:

- Organiser

One of the local social care service provider acted as organiser of the walks. They published the announcement in their networks and newspapers and also organised with other service providers for visits during lunch time or for coffee and cake.

- Guide

The tours were either guided by knowledgeable residents on historical points of interest or planned as walks through parks and recreational areas.

- Data collector

Most participants on the walks used a clipboard to note down points of interest, issues with the infrastructure (e.g. missing benches) and other noteworthy things.

- Data validator 
One of our participants checked the location of benches on the walks as provided by OpenStreetMap. If benches were missing on OSM, he added them; if benches were listed on OSM but not existent, they were deleted.

- Photographer

Overall, three older adults participated supported our data collection by taking pictures. Not all pictures could be taken during one of the walk, so all of them volunteered to visit points of interest again.

During the walks, a central topic that the participants discussed was the age-friendliness of the urban infrastructure. Since the discussion on the walks was recorded, valuable data on problems about and with the physical infrastructure was collected. Subsequently, the data was presented during one of the district council meetings in order to suggest improvements (e.g. installing new benches). The data collected on the walks was then used to co-create a walking guide that visualises the routes and provides the relevant information as well as appealing multi-media content that is meant to motivate older adults to explore their district jointly. In order to do so, a number of design workshops were conducted in which participant produced multi-media content.

\section{Phase 3: User testing}

In order to review the functionality of the app, which was developed in subsequent workshops and the quality of the data, a last walk was conducted where participants tested the digital public service by using the application on tablets. They were asked to review and discuss the functionalities, the relevance of the content and the quality of the data. This led to a number of usability and functional issues that had to be resolved.

\section{Summary: phases $1-3$}

Overall, the walkshops conducted helped us define and refine a service concept, co-create data and test the digital service developed. Table 2 provides a summary of the three different formats of walks. Participants in those walking workshops assumed a number of different roles, from explorer (what kind of walks are of interest to other older adults), to idea former (what kind of information may be of interest to others), to data creators and validators, users and testers of digital apps.

Table 2: Comparing different types of walking workshops

\begin{tabular}{|c|c|c|c|}
\hline & German city & German city & German city \\
\hline Type of walkshop & Ideation walk & Data co-creation walk & User test walk \\
\hline $\begin{array}{l}\text { Occurrence during } \\
\text { project }\end{array}$ & 1 & 6 & 2 \\
\hline Goals & $\begin{array}{l}\text { Defining relevant categories/ } \\
\text { information needs }\end{array}$ & $\begin{array}{l}\text { Collect data on pre-defined } \\
\text { categories }\end{array}$ & $\begin{array}{l}\text { User testing of the } \\
\text { new app }\end{array}$ \\
\hline $\begin{array}{l}\text { Number of } \\
\text { participants }\end{array}$ & 5 & $\begin{array}{l}\text { between } 5 \text { and } 20 \text { (usually with } \\
5 \text { active members) }\end{array}$ & $3-4$ \\
\hline $\begin{array}{l}\text { Type of } \\
\text { participants }\end{array}$ & $\begin{array}{l}\text { Older adults \& service } \\
\text { provider }\end{array}$ & Older adults \& service provider & Older adults \\
\hline $\begin{array}{l}\text { Roles of } \\
\text { participants }\end{array}$ & $\begin{array}{l}\text { Explorer } \\
\text { Idea former }\end{array}$ & $\begin{array}{l}\text { Navigator } \\
\text { Photographer } \\
\text { Note-taker }\end{array}$ & $\begin{array}{l}\text { User } \\
\text { Tester }\end{array}$ \\
\hline Duration & 60 minutes & $60-90$ minutes & 60 minutes \\
\hline
\end{tabular}




\begin{tabular}{|l|l|l|l|}
\hline Duration of event & $\sim 2$ hours & $\sim 2$ hours & $\sim 2$ hours \\
\hline Event makeup & Walk-discussion & Walk-break (coffee/lunch)-walk & Walk - debriefing \\
\hline Outcome & $\begin{array}{l}\text { Initial list of information } \\
\text { needs }\end{array}$ & Written responses on walks & $\begin{array}{l}\text { List of technical } \\
\text { issues }\end{array}$ \\
\hline
\end{tabular}

In the following, we evaluate how these walking workshops performed against our participation framework and allowed for the sharing of control by enabling an open and diverse co-creation process; the sharing of expertise by establishing participating older adults as experts and the enabling of change by addressing the needs and interests of participants and creating value for (other) older adults.

\section{Evaluation}

\section{Sharing control: Openness and diversity of data walkshops}

The district walks addressed all older people who were interested in exploring the district or the different neighbourhoods jointly. We made sure that the length and quality of the routes allowed a broad range of older adults to participate. This included also people with walking aides. In so doing, we wanted to include people for whom the technological aspect of the project might have been deterrent. Thus, we emphasized the value of local knowledge. The walks were well attended, but only a few participants engaged in other, more technology-related tasks of the process. The neighbourhood manager suggested that this was due to people's prime interest in neighbourhood walks, or more specifically only walks in particular neighbourhoods. She argued that this may have been due to people being interested in meeting acquaintances and being able to socialise during the walks rather than wanting to develop a digital district guide. She further suggested that participants were interested in the history of the district and wanted to learn. Judging from the number of participants per walk, we could clearly see that the two historical walks had the highest number of participants.

Two participants from the later formed design group confirmed that they experienced the recruitment strategy as open and accessible. One stated that she particularly liked the opportunity to 'have no barrier, just being able to see how it goes'. Another one stated that she liked the fact that people got 'lured out of their house'. A potential weakness identified by participants related to the socio-economic diversity of participants. The neighbourhood manager suggested that we mainly engaged senior citizens from the 'middle class'. This was confirmed by a participant from the core group who can be considered part of this 'middle class'. According to their view, the challenge was to get those people involved with low socio-economic status ('Getting them, that's the art'). Another participant, herself at this 'lower end of the income scale' by contrast observed that residents from the better-off neighbourhoods were missing, as they did not have as much of an incentive to leave their gardens for a walk as residents without private outdoor space.

As we organised the walks in collaboration with social care service providers, we mainly addressed those older adults who were already participating in their activities. In addition, others joint through newspaper announcements. Engagement may hence be moreeffectively secured through local service providers, as they are already involving a broad range of older adults from the district. The drawback may be that some people might not feel addressed by certain places/organisers (e.g. the church, a certain neighbourhood). What is hence important is too consider organising activities with 
different hosts and places in order to give a variety of people a chance to participate and engage in the process.

\section{Sharing expertise: Older adults as experts in co-creation processes}

The walks were important for establishing the participants as experts. While walking along routes and places that the participants knew well, they were given the opportunity to contribute their local and/or historical knowledge. Several participants described themselves as 'contemporary witnesses'. In particular, after conducting the data co-creation walks, the participants felt encouraged to share their historical and local knowledge. This experience remained an important point of reference also in subsequent, more technical workshops and meetings. For example, one of the female participants said that even though the men were more knowledgeable with technology, she could contribute with her knowledge about the district's history.

Overall, participants confirmed that they felt a sense of ownership over the resulting app. This was for example expressed through active involvement and shaping of the data co-creation:

- Participants suggested and planned routes/walks.

- Participants volunteered to guide a historical walk or facilitated contact with a local historian.

- A few participants from the core group regularly looked at the prototype and pointed out errors and missing data.

Not all participants were fully aware of the overall goals of the project. This was partly due to the different ways in which they had been invited. Some people only participated in one or two walks. In conversations along the way they stated that they did not have the time to commit to a longer project (e.g. because they were caring for a relative and simply took the opportunity to go on a walk because it fitted with their schedule this particular week) or they were not interested in further engaging with technology. The walks hence allowed a variety of people to contribute to the overall project, even if they did not engage in the prototyping part as such.

\section{Enabling change: Creating value for older adults}

Finally, we were interested in learning to what extent the process addressed the needs and interests of participants and thereby potentially enabled change. There was not one particular need to be satisfied with the co-creation process, but rather five overlapping interests:

- doing something for the home district or getting to know the district better,

- engaging with new technology,

- learning new things,

- doing something to improve the image of the neighbourhood/district, and

- socialising with others.

Most of the participants mentioned an interest in the district or a specific neighbourhood as motivation to join the process. For others, doing something for the home district was a strong motivation. One participant emphasised her sense of self-efficacy to be politically engaged and not to leave things to the politicians. Her participation in the process was part of her local political engagement and her interest in local history.

In particular, participants stated that they wanted to improve the image of the neighbourhood/district. This related strongly to the issue of segregation that was emphasised by the participating older adults as well as other stakeholders. For those who wanted to learn something 
about the district, the walks were relevant as well as for those who could share their knowledge. In addition, participants expressed an interest and the feeling to need to engage with new technology. This interest was based on their feeling of being socially excluded through non-use but also in a genuine interest in how software development 'works'.

All stakeholders we interviewed stated that the final digital service was relevant to older users. A social activities manager said, that 'going for a walk is much more part of the reality of older adults than of younger generations'. In addition to the overall relevance of walks for older adults the service providers, intermediaries and participants defined the value of the service for particular groups of older adults: Most emphasised the value for older people who do not know the district very well or have limited financial resources. The information provided also allowed for better planning of walks and hence increased people's confidence in being able to 'master' a walk in an unknown neighbourhood.

Hence, similar to accounts from other data walks, the participants were able to engage with their neighbourhoods in different ways. Drawing on an everyday activity such as walking and turning this experience into a digital public service, created value for different groups of older adults.

\section{Discussion and conclusion}

The re-use of open government data is part of the core objectives for civic co-creation projects (Sieber and Johnson, 2015), yet it is also one of the most demanding ones with respect to engaging (older) citizens. The co-creation of citizen-driven - rather than data-driven - digital entails a number of challenging activities:

(1) as part of the service co-creation, categories and objects of interest to citizens need to be defined;

(2) a survey about existing data concerning these objects needs to be conducted and their completeness needs to be assessed. This may lead to the collection and validation of data that have been identified as relevant but are not yet open or need to be collected across various data owners;

(3) subsequently, attributes for the objects need to be defined and data for these attributes collected;

(4) missing data need to be collected and/or co-created with citizens.

(5) The service and collected data need to be presented in a meaningful way to users.

(6) Editorial work (such as descriptions about data objects) is necessary, as well as the longterm maintenance of the data and the service.

Online information service designers adopting co-creation approaches therefore need to take into account that information identified as relevant by citizens may not be available as open data and plan ahead to collaborate with various data owners (e.g. service providers). They need to allow sufficient time for data creation and curation during co-creation processes. In addition, suitable methods for collecting and creating data as well as user-friendly interfaces to digitizing these data are required.

Above we presented data walkshops as a co-creation method to engaging older adults in the design of a digital neighbourhood guide and co-creation of open data. The three types of walks that we conducted were complementary with respect to how they facilitated the sharing of control and 
expertise, and enabled change for different groups of older citizens. The table below summarises how the different walking formats contributed to each of the co-creation principles and specifies the roles that citizens assumed.

Table 3: How data walks meet co-creation principles

\begin{tabular}{|c|c|c|c|c|}
\hline $\begin{array}{l}\text { Co- } \\
\text { creation } \\
\text { principles }\end{array}$ & Guiding questions & Ideation walk & Data co-creation walk & User test walk \\
\hline $\begin{array}{l}\text { Sharing } \\
\text { control }\end{array}$ & $\begin{array}{l}\text { How open and diverse } \\
\text { is the method? } \\
\text { Was a variety of } \\
\text { citizens included? } \\
\text { Who was excluded? }\end{array}$ & $\begin{array}{l}\text { Allowed to define } \\
\text { relevant categories } \\
\text { and articulate } \\
\text { information needs. } \\
\text { Role: Explorer }\end{array}$ & $\begin{array}{l}\text { Included planning of } \\
\text { walks (which route). } \\
\text { Allowed for a variety } \\
\text { of citizens to } \\
\text { participate (low } \\
\text { threshold, related to } \\
\text { everyday activities). } \\
\text { Role: Navigator }\end{array}$ & $\begin{array}{l}\text { Participants } \\
\text { evaluated the digital } \\
\text { app and suggested } \\
\text { further } \\
\text { improvements. } \\
\text { Role: Tester }\end{array}$ \\
\hline $\begin{array}{l}\text { Sharing } \\
\text { expertise }\end{array}$ & $\begin{array}{l}\text { (How) were } \\
\text { participants } \\
\text { established as } \\
\text { experts? } \\
\text { What kind of expertise } \\
\text { did they contribute? }\end{array}$ & $\begin{array}{l}\text { Participants defined } \\
\text { relevant categories } \\
\text { and information } \\
\text { needs based on } \\
\text { their own } \\
\text { experience. } \\
\text { Role: Idea former }\end{array}$ & $\begin{array}{l}\text { Participants collected } \\
\text { and validated data on } \\
\text { pre-defined } \\
\text { categories. } \\
\text { Roles: } \\
\text { Photographer, } \\
\text { Note-taker }\end{array}$ & $\begin{array}{l}\text { Participants } \\
\text { contributed with } \\
\text { feedback as life- } \\
\text { world expert. } \\
\text { Role: User }\end{array}$ \\
\hline $\begin{array}{l}\text { Enabling } \\
\text { change }\end{array}$ & $\begin{array}{l}\text { What were the needs } \\
\text { and interests that } \\
\text { motivated participants } \\
\text { to join? } \\
\text { To which extent and } \\
\text { how did the } \\
\text { interventions address } \\
\text { these needs, interests } \\
\text { and motivations? } \\
\text { How relevant, } \\
\text { interesting and useful } \\
\text { were the } \\
\text { interventions? } \\
\text { Did the process have } \\
\text { any relevance beyond } \\
\text { the participants? }\end{array}$ & \multicolumn{3}{|c|}{$\begin{array}{l}\text { Data walkshops catered for participants' interest for their/in } \\
\text { neighbourhoods (and their improvements). } \\
\text { Data walkshops allowed participants to discover their neigh } \\
\text { (anew), including those with mobility issues, other commitm } \\
\text { (e.g. caring for a relative) or financial constraints. }\end{array}$} \\
\hline
\end{tabular}

Overall, our findings suggest that for older adults data walking workshops proved to be an effective and satisfactory form of engagement. This age group has a sustained interest and knowledge about their neighbourhoods and what it means to grow older in a particular place. Walks combine a social aspect with physical activity-both are viewed as having a positive effect on health and well-being. Furthermore, giving older adults the opportunity to share their experiences and knowledge was appreciated by the participants. Collecting this information and making it available in a digital service further values the participants and at the same time is beneficial to a broader target audience. 
Hence, using this experimental form of engagement allows not only for critically engaging with data (Van Zoonen et al., 2017; Wieringa and van Es, 2018; Hunter, 2018; Powell, 2018), but also to engage a variety of citizens in civic tech activities to co-design, implement and evaluate digital public services that benefit their communities. Data walks are a promising method to facilitate 'participatory open data projects' (Sieber and Johnson, 2015) by engaging citizens that are often excluded as partners in digital innovation. They are a method to enrich the current civic tech formats and allow a variety of citizens to engage with data about their neighbourhoods, districts and cities in a meaningful way. Such walkshops may attract participants beyond the "usual suspects", but they are also in themselves a meaningful activity to contribute to social participation. Hence, even if not all participants of walkshops continue their engagement in the digital service development, they still benefit from participating in and contributing to the process and its outcome. What needs to be admitted is that not everybody is willing or able to participate in a longer-term process.

Nevertheless, such walks provide an opportunity for any community members to become involved selectively.

The data walkshops as described here were part of a larger co-creation project to design and implement a digital neighbourhood guide. There are a number of pre-conditions that framed the ways in which the co-creation project, in general, and the walks, in particular, were framed. These relate to the existing collaborations of local stakeholders and the existing services they provide to residents. Conducting effective co-creation activities means to get such local stakeholders on board and include them in the recruitment of participants. If a digital service is to be developed that is sustainable and maintained after a project ends, the service needs to contribute to their service portfolio. Existing open data are important to consider, some will already be used for the delivery of existing services. However, data maintenance is a key challenge of participatory open data projects and it is important to consider how newly created data will be maintained after a project terminates.

In conclusion, there is a clear tension between data-driven app development and citizen-driven service co-creation as much of the information identified as relevant in co-creation processes is not necessarily available as open data. We argue that effective and relevant services for older adults should not be driven by what data is available, but rather have to be based on the needs and requirements of the target audience. Through the pilot work presented above, we identify that data walkshops provide a way of engaging older adults in the co-creation of data and digital public services. Through such interventions, older adults cease to be subjects of digital innovation and become co-designers. Age and ageing are not merely understood as a problem that needs a technological fix, but rather older adults' expertise and lived experience become resources for the co-creation of value, knowledge and technology.

\section{Acknowledgements}

This co-creation project would not have been possible without the support of the many older residents and local social care service providers in Bremen Hemelingen. In particular, I would like to thank the district council and the Netzwerk Alte Vielfalt. In addition, I would like to thank my colleagues Herbert Kubicek and Ulrike Gerhard for being such a fantastic team. Thanks to Frank Reins and Frank Berker from our MobileAge project for joining us on the walks and this co-creation journey. Thank you, Jo Bates for your valuable and constructive feedback on an earlier version of this manuscript.

MobileAge has received funding from the European Union's Horizon 2020 research and innovation programme under grant agreement No 693319 


\section{References}

Beneito-Montagut, R., Cassián-Yde, N., Begueria, A., 2018. What do we know about the relationship between internet-mediated interaction and social isolation and loneliness in later life? Qual. Ageing Older Adults 19, 14-30. https://doi.org/10.1108/QAOA-03-2017-0008

$B \emptyset \mathrm{dker}, \mathrm{S}$., 2006. When second wave $\mathrm{HCl}$ meets third wave challenges, in: Proceeding NordiCHI '06 Proceedings of the 4th Nordic Conference on Human-Computer Interaction: Changing Roles. Oslo.

Bratteteig, T., Wagner, I., 2016. Unpacking the notion of participation in Participatory Design. Comput. Support. Coop. Work CSCW 25, 425-475.

Carroll, J.M., Rosson, M.B., 2007. Participatory design in community informatics. Des. Stud. 28, 243261. https://doi.org/10.1016/j.destud.2007.02.007

Ehn, P., 2008. Participation in Design Things, in: Proceedings of the Tenth Anniversary Conference on Participatory Design 2008, PDC'08. Indiana University, Indianapolis, IN, USA, pp. 92-101.

European Commission, 2014. ICT-enabled public sector innovation in H2020 [WWW Document]. URL http://ec.europa.eu/digital-agenda/en/news/ict-enabled-public-sector-innovation-h2020flyer (accessed 1.23.14).

Gidlund, K.L., 2012. Designing for all and no one - practitioners understandings of citizen driven development of public e-services, in: Proceedings of the 12th Participatory Design Conference on Research Papers: Volume 1 - PDC'12. Presented at the the 12th Participatory Design Conference, ACM Press, Roskilde, Denmark, p. 11. https://doi.org/10.1145/2347635.2347638

Gooch, D., Forbes, H., Mackinnon, J., Macpherson, R., Walton, C., Barker, M., Hudson, L., Kelly, R., Kortuem, G., Linden, J.V.D., Petre, M., Brown, R., Klis-Davies, A., 2018. Amplifying Quiet Voices: Challenges and Opportunities for Participatory Design at an Urban Scale. ACM Trans. Comput.-Hum. Interact. 25, 1-34. https://doi.org/10.1145/3139398

Greenfield, A., Kim, N., 2011. Systems/layers: how to run a walkshop on networked urbanism. [WWW Document]. URL http://diffusion.org.uk/ebooks/Systems_Layers_classic_landscape_40pp_A4.pdf (accessed 10.24.18).

Guest, G., MacQueen, K., Namey, E., 2012. Applied Thematic Analysis. SAGE Publications, Inc., 2455 Teller Road, Thousand Oaks California 91320 United States. https://doi.org/10.4135/9781483384436

Hayes, G.R., 2011. The Relationship of Action Research to Human-computer Interaction. ACM Trans Comput-Hum Interact 18, 15:1-15:20. https://doi.org/10.1145/1993060.1993065

Hogge, B., 2010. Open data study.

Höppner, G., Urban, M., 2018. Where and How Do Aging Processes Take Place in Everyday Life? Answers From a New Materialist Perspective. Front. Sociol. 3. https://doi.org/10.3389/fsoc.2018.00007

House - Oversight and Government Reform, 2007. S.2488 - OPEN Government Act of 2007 [WWW Document]. URL https://www.congress.gov/110/plaws/publ175/PLAW-110publ175.pdf (accessed 9.27.16).

Hunter, D., 2018. Data Walking. Ravensbourne Publications, London.

Janssen, M., Charalabidis, Y., Zuiderwijk, A., 2012. Benefits, Adoption Barriers and Myths of Open Data and Open Government. Inf. Syst. Manag. 29, 258-268. https://doi.org/10.1080/10580530.2012.716740

Jarke, J., Gerhard, U., 2018. Using Probes for Sharing (Tacit) Knowing in Participatory Design: Facilitating Perspective Making and Perspective Taking. -Com 17, 137-152. https://doi.org/10.1515/icom-2018-0014

Kanstrup, A.M., Bertelsen, P., Østergaard Madsen, J., 2014. Design with the feet: walking methods and participatory design, in: PDC '14 Proceedings of the 13th Participatory Design 
Conference: Research Papers - Volume 1. Presented at the PDC'14, ACM, New York, NY, USA, pp. 51-60.

Laslett, P., 1991. A fresh map of life: the emergence of the Third Age, 1st Harvard University Press pbk. ed. ed. Harvard University Press, Cambridge, Mass.

Lee, M., Almirall, E., Wareham, J., 2015. Open Data and Civic Apps: First-generation Failures, Secondgeneration Improvements. Commun ACM 59, 82-89. https://doi.org/10.1145/2756542

Manchester, H., Facer, K., 2016. (Re)-learning the city for intergenerational exchange, in: Sacré, H., De Visscher, S. (Eds.), Learning the City: Cultural Approaches to Civic Learning in Urban Spaces, SpringerBriefs in Education. Springer International Publishing, Cham s.l, pp. 83-98.

Nambisan, S., Nambisan, P., 2013. Engaging Citizens in Co-Creation in Public Services Lessons Learned and Best Practices. IBM Center for The Business of Government, Washington, DC.

Neven, L., 2011. Representations of the Old and Ageing in the Design of the New and Emerging. Assessing the design of Ambient Intelligence technologies for older people.

Office of the President, 2009. Memorandum for the Heads of Executive Departments and Agencies 39-09 [WWW Document]. whitehouse.gov. URL https://www.whitehouse.gov/the-pressoffice/memorandum-heads-executive-departments-and-agencies-3-9-09 (accessed 9.27.16).

Peine, A., Faulkner, A., Jæger, B., Moors, E., 2015. Science, technology and the 'grand challenge' of ageing-Understanding the socio-material constitution of later life. Technol. Forecast. Soc. Change 93, 1-9. https://doi.org/10.1016/j.techfore.2014.11.010

Powell, A., 2018. The data walkshop and radical bottom-up data knowledge, in: Knox, H., Nafus, D. (Eds.), Ethnography for a Data-Saturated World, Materialising the Digital. Manchester University Press, Manchester.

Presidential Directives EO 13392, 2005. Improving Agency Disclosure of Information [WWW Document]. URL http://fas.org/irp/offdocs/eo/eo-13392.htm (accessed 9.27.16).

Sanders, E.B.-N., Stappers, P.J., 2008. Co-creation and the new landscapes of design. CoDesign 4, 518. https://doi.org/10.1080/15710880701875068

Schrock, A.R., 2016. Civic hacking as data activism and advocacy: A history from publicity to open government data. New Media Soc. https://doi.org/10.1177/1461444816629469

Sieber, R.E., Johnson, P.A., 2015. Civic open data at a crossroads: Dominant models and current challenges. Gov. Inf. Q. 32, 308-315. https://doi.org/10.1016/j.giq.2015.05.003

Star, S.L., Griesemer, J.R., 1989. Institutional Ecology, 'Translations' and Boundary Objects: Amateurs and Professionals in Berkeley's Museum of Vertebrate Zoology, 1907-39. Soc. Stud. Sci. 19, 387-420. https://doi.org/10.1177/030631289019003001

Van Zoonen, L., Hirzalla, F., Engelbert, J., Zuijderwijk, L., Schokker, L., 2017. Seeing more than you think: a data walk in the city. Bang Table Community Engagem. Blog. URL https://www.bangthetable.com/blog/data-walk-in-smart-city/ (accessed 2.14.19).

Vines, J., Clarke, R., Wright, P., McCarthy, J., Olivier, P., 2013. Configuring participation: on how we involve people in design, in: Proceedings of the SIGCHI Conference on Human Factors in Computing Systems Pages. Presented at the CHI 2013, ACM Press, pp. 429-438. https://doi.org/10.1145/2470654.2470716

Vines, J., Pritchard, G., Wright, P., Olivier, P., Brittain, K., 2015. An Age-Old Problem: Examining the Discourses of Ageing in $\mathrm{HCl}$ and Strategies for Future Research. ACM Trans. Comput.-Hum. Interact. 22, 1-27. https://doi.org/10.1145/2696867

Voorberg, W.H., Bekkers, V.J.J.M., Tummers, L.G., 2015. A Systematic Review of Co-Creation and CoProduction: Embarking on the social innovation journey. Public Manag. Rev. 17, 1333-1357. https://doi.org/10.1080/14719037.2014.930505

Wanka, A., Gallistl, V., 2018. Doing Age in a Digitized World-A Material Praxeology of Aging With Technology. Front. Sociol. 3. https://doi.org/10.3389/fsoc.2018.00006

Wieringa, M., van Es, K., 2018. Walking as method in data studies.

Wiles, J.L., Leibing, A., Guberman, N., Reeve, J., Allen, R.E.S., 2012. The Meaning of "Aging in Place" to Older People. The Gerontologist 52, 357-366. https://doi.org/10.1093/geront/gnr098 